\title{
ENTREVISTA COM O PROF. ANTONIO NÓVOA
}

\author{
Lucíola Licínio DE C. P. SANTOS*
}

$\mathrm{O}$

prof. Antonio de Sampaio Nóvoa está no seu segundo mandato como reitor da Universidade de Lisboa (períodos de 2006 a 2009 e 2009 a 2013) É um acadêmico muito conhecido no Brasil, sobretudo a partir de 1992, quando o seu texto "Formação de professores e profissão docente", capítulo do livro por ele organizado, Os professores e a sua formação, foi lançado em nosso país, tornando-se uma referência no campo acadêmico. A partir de então, algumas de suas obras como: O método (auto)biográfico e a formação, Profissão: professor, Vidas de professores, Reformas educativas e formação de professores e As organizações escolares em análise $e^{1}$ passaram a constar em grande parte da bibliografia de dissertações, teses, artigos e livros dos profissionais da educação. Sem dúvida, nestas duas últimas décadas tem sido um dos autores mais citados na área educacional brasileira, principalmente no campo da formação de professores.

Nóvoa é professor catedrático do Instituto de Educação da Universidade de Lisboa e já lecionou em diversas universidades da Europa e dos Estados Unidos como professor convidado. É doutor em Ciências da Educação pela Universidade de Genebra e doutor em História pela Universidade de Paris IV-Sorbonne. Sua tese de doutorado constitui-se em um estudo sobre o desenvolvimento da profissão docente e marcou sua posição no campo da história da Educação. Ao lado disso, tem uma produção relevante na área da Educação Comparada.

Esta entrevista está centrada em questões relacionadas ao ensino superior, buscando revelar como um acadêmico da área da educação, que dirige uma universidade, percebe, interpreta e reflete sobre a realidade e os desafios que este nível de ensino enfrenta. Como os leitores poderão constatar, as respostas de Nóvoa às minhas perguntas revelam um dirigente que identifica com clareza os principais problemas que o ensino superior enfrenta e que se diz comprometido com valores sociais e políticos que apontam para a democratização da universidade, entendida como ampliação da matrícula aliada a uma formação profissional de qualidade e a uma produção acadêmica, voltada para a criação de um corpo de conhecimentos sólidos e de relevância social. * Doutora em Educação e professora da Faculdade de Educação da Universidade Federal de Minas
Gerais. E-mail: luciolaufmg@yahoo.com.br 
Durante todo o contato que mantive com Nóvoa, apesar de sempre apressado, em função das demandas de sua agenda, mostrou ser uma pessoa simples, atenciosa e extremamente cordial. De todos os seus traços de personalidade, o que mais me cativou foi seu grande senso de humor, o que o torna ainda mais interessante como pessoa e intelectual.

Tenho certeza de que esta entrevista se constitui em uma leitura estimulante e valiosa, sobretudo, para todos os que se interessam, trabalham e/ou pesquisam sobre o ensino superior e políticas públicas.

Belo horizonte, 2 de fevereiro de 2012.

P: Quais são as propostas e as ações que veem orientando seu trabalho e de sua equipe à frente da Universidade de Lisboa?

AN: Na Universidade de Lisboa estamos a actuar, neste momento, em duas direcções principais. A primeira é uma reorganização dos cursos, rompendo com uma excessiva especialização (sobretudo no $1^{\circ}$ ciclo) e procurando assegurar uma formação de base, científica e cultural, em grandes áreas do conhecimento (e, nalguns casos, em novas áreas interdisciplinares). Estamos a pensar a nossa oferta de formação não apenas dentro da geometria tradicional das faculdades, mas sugerindo formas de articulação e de coordenação transversal. Não quero ser demasiado optimista, mas julgo que começamos a ver alguns frutos. Dou-lhe como exemplo a criação de uma nova licenciatura em Ciências da Saúde, transversal à Universidade de Lisboa, com contributos de cinco faculdades (Medicina, Ciências, Farmácia, Medicina Dentária e Psicologia). Este é um exemplo concreto - podia dar-lhe outros - de um trabalho de reorganização da oferta de formação, que está a ser realizado com prudência, mas com uma visão de futuro. Hoje, o mais interessante passa-se nas fronteiras e nos cruzamentos. O futuro passa pela convergência entre várias disciplinas, pela interligação entre áreas distintas, pela fertilização mútua entre grupos científicos. Para tal, são necessários ambientes que apenas as instituições universitárias, na sua diversidade, podem proporcionar.

A outra linha de trabalho prende-se com a orientação dos estudos e novos modos de organização do trabalho universitário. O que é que isto quer dizer? Quer dizer que o aconselhamento dos estudantes, a tutoria e o seu enquadramento têm hoje uma centralidade que não tinham no passado. Quando olhamos para as práticas de prestigiadas universidades internacionais (por exemplo, Harvard ou Oxford), vemos a importância que este assunto adquire.

A diversidade de percursos, a mobilidade e a ligação entre os diferentes ciclos de estudos exigem uma atenção muito grande ao enquadramento e à orientação 
dos estudantes, sobretudo nos primeiros anos. Não podemos continuar a olhar com indiferença para as percentagens assustadoras de estudantes que têm insucesso ou que abandonam os estudos logo nos primeiros anos.

Estamos a consolidar estruturas que possam assumir-se como lugares de orientação dos estudos, que ajudem os alunos a enquadrar-se nas lógicas de Bolonha. Seguir um percurso de dois ciclos (licenciatura e mestrado)? Fazer uma licenciatura e, depois de uma experiência profissional, regressar à universidade para frequentar um mestrado? Realizar outro tipo de percurso escolar? É preciso que os estudantes encontrem espaços onde possam debater e construir os seus próprios caminhos.

Ao lado destas estruturas, já criámos um observatório que nos ajudará a conhecer melhor os nossos estudantes, a analisar os fenómenos de insucesso e de abandono escolar, a avaliar as estratégias de inserção dos nossos diplomados no mercado de trabalho. Este observatório é um instrumento essencial para a Universidade de Lisboa.

\section{P: Quais os principais desafios que vem enfrentando como reitor da Universidade de Lisboa?}

AN: Estamos enfrentando tempos de mudança e de combate. A mudança tem três palavras: mais mundo, mais liberdade, mais conhecimento. Mais mundo, uma maior abertura da universidade à sociedade. A consciência nítida de que não há universidades nacionais e de que a viagem, a mobilidade e o cosmopolitismo são, hoje, a condição da vida dos jovens e do trabalho científico. Mais liberdade, liberdade das pessoas e das instituições, independência e afirmação do espírito crítico, o melhor que podemos dar para pensar e renovar Portugal. Mais conhecimento, numa perspectiva de ligação entre o ensino e a ciência, de centralidade da investigação na universidade. Talvez Fernando Pessoa pudesse ter dito: Criar é preciso; viver não é preciso. A criação como eixo do trabalho universitário.

Mas têm sido também tempos de combate. Nos últimos anos, o princípio do valor económico das universidades tem-se sobreposto a todos os outros, contribuindo para a sua mercantilização. Longe parecem os tempos em que se podia dizer da universidade que ela era o lugar no qual se protegia o trabalho sem valor económico imediato, como escreveu Eliot Freidson. O "capitalismo académico" tem emergido por todo lado, como se não houvesse outra saída para as instituições. A adesão de muitos universitários a estes princípios e a resignação de quase todos os outros levam-me a considerar ainda mais imprescindível resistir aos interesses dominantes, sejam eles económicos ou políticos.

Procuro encontrar o meu caminho inspirado por uma vontade de mudança que vai muito para além da "mudança morta" das lógicas reformadoras. A universidade deve ser uma instituição diferente das outras e é nessa diferença que encontra a sua razão de ser. Vergada à ditadura do pensamento inevitável, torna-se inútil e 
dispensável. Acredito que a universidade se deve orientar pelo "princípio de resistência incondicional", como escreve Jacques Derrida.

P: Portugal vive hoje uma profunda crise econômica que, sem dúvida, deve estar repercutindo na universidade, sobretudo pelos cortes orçamentais. Como tem sido dirigir a Universidade em meio a esta situação?

AN: De acordo com todos os indicadores publicados pela Organização para a Cooperação e Desenvolvimento Económico (OCDE), Portugal é um dos países que tem níveis mais baixos de investimento no ensino superior. A despesa por estudante em Portugal é mais baixa do que em qualquer outro país europeu. Dou-lhe mesmo um dado curioso e estranho: em Portugal, contrariamente ao resto do mundo, um estudante do ensino superior é mais "barato" do que um aluno do ensino secundário ou mesmo do que um aluno de um curso de formação profissional?!

O comissário europeu da Educação, Ján Figel, tem alertado para o subfinanciamento crónico das universidades europeias. No caso português a situação é bem pior. Estes cortes são cegos, pois o governo não promoveu qualquer medida de fundo, do ponto de vista legal, que desse às universidades os instrumentos necessários à sua reforma. Parece que o governo não quis fazer as coisas difíceis, as reformas de fundo, limitando-se apenas a cortar de forma cega.

Esta política empurra as instituições para as políticas mais medíocres: sem os instrumentos legais para as reformas de fundo, são obrigadas a cortar o que podem, desde as despesas de funcionamento (degradação dos edifícios, diminuição de horários de abertura de laboratórios e bibliotecas etc.) até a denúncia dos contratos mais precários, mas que são, muitas vezes, os mais importantes para a renovação das instituições (jovens cientistas, docentes em princípio de carreira, profissionais com estatuto de convidados, entre outros). É claro que, se o país não tem dinheiro, temos de assumir com coragem a necessidade de reduzir despesas. Mas isso faz-se com políticas sérias, que permitam às universidades ter estratégias de reforma e de reorganização. Não se faz com cortes cegos, sem dar às instituições os instrumentos necessários para as mudanças que o novo cenário impõe.

P: Está na ordem do dia a proposta da fusão da Universidade de Lisboa com a Universidade Técnica de Lisboa, processo este em que o senhor esteve na liderança. Quais as vantagens desta proposta e o que é preciso para concretizá-la com sucesso?

AN: Há muito tempo que se fala da necessidade de reorganização da rede do ensino superior em Portugal. Para isto, é necessário muita determinação e uma grande capacidade de diálogo. A confiança mútua é essencial para o êxito deste caminho. Mas é evidente que precisamos, em Portugal, de instituições com mais "massa crítica" e com uma maior dimensão que lhes permita competirem no espaço europeu do ensino superior. 
Estas propostas apontam para um enriquecimento mútuo das instituições, no respeito pelas suas histórias e identidades, e no quadro de uma diversidade de formações. Não está em causa acabar com essa diversidade. O que queremos é que ela se organize no contexto de uma instituição mais forte, com maior capacidade de intervenção na sociedade. Não é uma questão de tamanho ou de dimensão. Precisamos, sim, de reconstituir uma universidade que tenha as dimensões "clássicas" e "técnicas", reunindo assim a universalidade dos saberes.

Este processo só terá êxito se toda a gente ganhar: se ganhar a Universidade de Lisboa, alargando o seu âmbito de acção; se ganhar a Universidade Técnica de Lisboa, ampliando seu espaço institucional, se ganhar o país, ou seja, se as soluções que viermos a encontrar forem positivas e úteis para a reorganização da rede de ensino superior. Estamos a dar um sinal muito importante aos responsáveis políticos, aos universitários e à sociedade portuguesa no seu conjunto. Vivemos este processo com grande responsabilidade e determinação, mas não desconhecemos as dificuldades para o levar a bom termo.

Neste caso, orgulhamo-nos de ter dado os primeiros passos. Porque sabemos que nada se fará sem uma vontade própria das instituições. "De cima”, podemos e devemos criar as condições para que o trabalho conjunto se desenvolva. Mas só a partir "de baixo" ele poderá concretizar-se com sucesso.

P: O governo português criou um programa de ingresso direto de pessoas maiores de 23 anos na universidade. Qual é sua opinião sobre este programa e como ele vem sendo implementado?

AN: A questão dos novos públicos é fundamental. Colocou-se em muitos países, por exemplo no Canadá, há cerca de 30 anos; e, na Europa, há cerca de 15 ou 20 anos. É um assunto que conheço bem. É muito interessante para mim estar hoje, como reitor, a trabalhar matérias que foram temas centrais da minha própria formação universitária e da minha actividade como investigador 20 anos atrás.

Quando o governo criou a possibilidade de os maiores de 23 anos se candidatarem directamente à Universidade, organizámos um sistema inovador para a realização das provas de acesso. Julgo que se conseguiram definir com rigor procedimentos que têm em conta não apenas a escolaridade anterior, mas também um conjunto de capacidades e de disposições para a frequência do ensino superior. Em todo o processo, temos procurado valorizar a experiência pessoal e profissional, mas há ainda um longo caminho a percorrer.

Mas, para além deste primeiro momento - a selecção dos estudantes - há outros dois ainda mais importantes. Por um lado, o acolhimento destes adultos e o reconhecimento da sua experiência profissional anterior, pois não se pode tratar uma pessoa 
de 35 anos que entra para a universidade da mesma maneira que se trata um jovem de 18 anos que acabou de concluir o ensino secundário. É preciso criar estruturas de acolhimento destes públicos e de reconhecimento da sua experiência profissional - a famosa creditação ou validação dos adquiridos (tema de grande debate no Canadá no início dos anos de 1980).

Por outro lado, estes adultos devem seguir percursos universitários e ter condições de frequência dos cursos que facilitem uma articulação com a sua vida profissional (horários nocturnos, e-learning, dispositivos de avaliação etc.).

O acesso, a creditação da experiência e a criação de condições adequadas são três momentos que devem ser definidos com rigor e permanente acompanhamento e avaliação. Caso contrário, perderemos mais uma oportunidade de contribuir utilmente para a qualificação dos portugueses e, ao mesmo tempo, para a renovação das instituições. É um desafio que não pode ser perdido.

P: A literatura educacional tem levantado muitas questões sobre o Processo de Bolonha. Como o senhor vê as políticas decorrentes deste programa?

AN: Apesar do Processo de Bolonha traduzir uma vontade de abertura do ensino superior a mais estudantes, está a correr mal, porque há muita cosmética e pouca mudança efectiva. Alterou-se a duração dos cursos e, nalguns casos, a sua designação. Avançou-se para uma descrição dos cursos através dos créditos europeus (ECTS), ${ }^{2}$ mas não se tocou no aspecto central: uma nova organização do trabalho universitário, centrado nos estudos, na aprendizagem e na proximidade às práticas de investigação (laboratórios, bibliotecas, recursos on-line etc.).

Alia-se a isto a visão economicista de todo o programa de Bolonha, com a redução dos cursos de graduação a três anos. Corre-se, assim, o risco de massificar o ensino superior à custa da qualidade da formação. $\mathrm{O}$ argumento da "aprendizagem ao longo da vida", isto é, a ideia de que o estudante voltará à universidade mais tarde para novas formações, não é suficiente para eliminar o perigo de uma desvalorização dos diplomas. O pior que se pode fazer a um estudante, sobretudo oriundo de um meio pobre, é acenar-lhe com a miragem de um diploma que, uma vez obtido, de pouco ou nada serve. Se a universidade não for um lugar de mobilidade social, perde muita da sua razão de ser.

A empregabilidade é, talvez, um dos maiores equívocos do Processo de Bolonha ou, pelo menos, do modo como ele tem sido concretizado. É impossível conceder um diploma universitário, profissionalizante, no final de um ciclo de estudos de três anos. Para se conseguir aprender ao longo da vida são necessárias bases sólidas, científicas e culturais.

Como se escreve num importante documento da League of European Research Universities (Leru - Liga das Universidades Europeias de Investigação): “As qualidades 
de que tanta gente fala - empreendedorismo, capacidade de gestão, liderança, visão, trabalho de grupo, adaptabilidade e capacidade de aplicar conhecimentos técnicos - não são características primárias, mas decorrem da capacidade de pensar, de argumentar e de conhecer".

No que diz respeito à pesquisa, as tendências de Bolonha são contraditórias. Por um lado, há um desenvolvimento importante dos estudos pós-graduados (mestrados e doutoramentos), o que promove uma maior lógica de pesquisa no seio do espaço universitário. Por outro lado, ao promover uma "massificação do ensino", Bolonha obriga a um esforço acrescido do ponto de vista da formação dos estudantes, deixando menos tempo livre para o trabalho de investigação. Por isso, alguns centros de pesquisa de excelência manifestam tendências de separação das universidades, o que seria gravíssimo. Só o futuro dirá o que vai acontecer.

P: E do ponto de vista do ensino, quais têm sido as principais repercussões do Processo de Bolonha?

AN: É necessário clarificar alguns pontos. Há um discurso dominante que tende a transportar, para o ensino superior, práticas e conceitos que se revelaram problemáticos no ensino básico e secundário. Curiosamente, são as mesmas pessoas que fizeram a crítica destes conceitos que, agora, os propõem para a universidade. Fico sempre muito desconfiado destas apropriações, para não dizer conversões. Deixe-me dar-lhe três exemplos. Primeiro: o conceito de competências, tão criticado pela utilização que dele fizeram os pedagogos, tem sido, agora, largamente celebrado no âmbito do Processo de Bolonha. Segundo: a mudança de paradigma, do "ensino" para a "aprendizagem", que agora parece suscitar um certo consenso, esteve na origem das críticas principais à pedagogia e à sua intenção de "colocar o aluno no centro do sistema". Terceiro: a "reforma global do ensino superior" surge, agora, como a solução de futuro para as universidades quando, ainda há pouco tempo, toda a gente criticava a "reformite aguda" que teria contribuído para minar o ensino básico e secundário. Julgo que devemos manter uma vigilância crítica e não embarcar, de ânimo leve, nestas três derivas: as competências, o aluno no centro, a reforma global. Parece-me, pelo contrário, que devemos pensar Bolonha a partir da valorização do estudo - de uma "reforma dos estudos", como dizia Verney -, isto é, da capacidade de organizar o trabalho universitário em torno da leitura e da utilização das bibliotecas, da experimentação e da frequência aos laboratórios, das práticas de investigação, do estudo autónomo e do estudo acompanhado (tutoria, supervisão, entre outras). Dito de outro modo: temos de ir além de uma lógica de aulas e de estruturas curriculares rígidas, valorizando o estudo, nas suas diversas dimensões, como referência principal do trabalho universitário. E, ao mesmo tempo, temos de conceber a mudança como processo permanente de inovação e de avaliação, não mitificando as capacidades transformadoras das "grandes reformas legislativas". 
P: Cada vez mais, as universidades do mundo inteiro buscam parcerias com as empresas privadas. No seu ponto de vista, estas parcerias são importantes? Elas não ameaçam a autonomia da universidade e suas finalidades públicas, ao colocá-la a serviço de interesses empresariais?

AN: $\mathrm{O}$ apoio das empresas às universidades é muito bem-vindo. Mas é preciso ter cuidado para não importar uma lógica empresarial para dentro da educação superior. As universidades são uma das invenções mais notáveis da humanidade, lugar dos maiores progressos e descobertas científicas, dos grandes avanços do conhecimento e da cultura. E tal só foi possível porque as universidades estavam protegidas de interesses imediatos, porque foram capazes de se construírem (ou, pelo menos, de se imaginarem, o que já não é pouco) como espaços de um tempo e de uma liberdade sem condição. Se a sociedade as forçar à ditadura do imediato, a uma lógica produtivista e de rendibilidade, se as constranger à adopção de medidas de puro oportunismo gestionário, desumanizadoras, tornar-se-ão, a prazo, instituições inúteis e dispensáveis.

P: Os professores das universidades públicas brasileiras têm se queixado das pressões exercidas sobre seu trabalho, principalmente aquelas decorrentes do controle imposto pelo sistema de avaliação vigente hoje nas universidades. Como o trabalho docente tem sido afetado por esta cultura da avaliação, que domina o meio acadêmico nos dias atuais?

AN: Ninguém ignora que o chamado "Estado avaliador" tem inventado formas novas, e mais sofisticadas, de burocracia e de controlo. Há dois desvios da avaliação que me parecem perniciosos. Por um lado, a elaboração de rankings que tendem a transformar o ensino superior num campeonato sem sentido. Por outro lado, a tendência para intensificar o trabalho docente, isto é, para exigir dos professores cada vez mais tarefas (ensino, investigação, gestão, serviço à comunidade...), tornando muito difícil o dia a dia da profissão universitária.

Em decorrência desta situação, um certo mal-estar vem se instalando junto dos professores, devido à falta de condições de trabalho, mas sobretudo devido à intensificação e burocratização a que tem estado sujeita a profissão académica. Cada vez mais tarefas e missões, cada vez mais burocracia, cada vez menos tempo para as missões fundamentais que definem um universitário: o ensino e a investigação. Com energia e inteligência temos de encontrar solução para esta encruzilhada.

P: O senhor, que já manteve contactos com universidades de diferentes países, poderia nos dizer, no cenário atual, que experiência ou que proposta de trabalho lhe chamou mais a atenção?

AN: Conheço bem as universidades europeias, norte-americanas e sul-americanas, mas nunca tinha visitado as universidades chinesas. É uma realidade impressionante, tal o investimento que a China está a fazer no ensino superior. Impressionante do ponto de vista das infraestruturas e equipamentos, dos esforços de 
qualificação do pessoal docente, de tentativa de aproximação às universidades de referência no mundo.

Refiro apenas dois aspectos. Primeiro, a grande preocupação com o serviço à sociedade. As universidades têm como um de seus objetivos desenvolver em seu interior lógicas de inovação, de transferência tecnológica, de apoio ao desenvolvimento. A relevância social e a aplicabilidade dos conhecimentos são um tema constante.

A segunda dimensão aponta para palavras de ordem assumidas com grande determinação: queremos ser os melhores, queremos ter as melhores instituições, queremos ser instituições de referência, não só no plano interno da China, mas num quadro de competitividade global, queremos ter os melhores e mais talentosos estudantes, queremos ter um corpo docente altamente qualificado.

Este discurso existe também na sociedade portuguesa. E ainda bem. A diferença reside no facto de os chineses considerarem que nada será obtido sem um reforço e uma consolidação das instituições universitárias, ao passo que, em Portugal, parece apostar-se numa "erosão" das universidades como forma de abrir espaço para a emergência de outras instituições. Quais?!

Quem ocupa lugares de poder tem o dever de criar os instrumentos para a reforma e para a mudança das instituições, não se limitando a dissertar levianamente sobre a "irreformabilidade das universidades". Neste caso, a leviandade é sinónimo de demissão e de resignação. A China está a dar uma grande lição no plano da renovação do tecido universitário a partir de uma renovação e de um reforço das suas instituições. É um país com grandes ambições e com as condições e os recursos para tornar realidade num futuro próximo.

P: O que considera importante para que a universidade consiga desenvolver-se cumprindo seu papel social, sem se curvar a cada onda de reformas que lhe são impostas, e com competência para superar seus problemas crônicos?

AN: Nos últimos anos, houve uma transformação de fundo na universidade portuguesa, que hoje acolhe mais de um terço dos jovens da faixa etária dos 18 aos 23 anos. A obtenção de um diploma do ensino superior começa a ser requisito indispensável para uma participação efectiva nas sociedades do século XXI, ditas do conhecimento. No caso da Universidade de Lisboa, cerca de metade dos nossos estudantes frequenta estudos pós-graduados. Em poucos anos, a universidade mudou mais do que ao longo do todo o século XX.

Neste cenário, há três problemas que me parecem centrais para o futuro das universidades. O primeiro prende-se com a passagem de uma lógica de consumo para uma lógica de criação. $O$ futuro das universidades passa pela criação, obviamente pelo lado da investigação e da ciência, mas também pelo lado da invenção, das artes, da 
cultura, da participação social. É tempo de avançar um passo mais e de colocar a criação, nas suas mais diversas formas, no centro da vida universitária. Criação cultural. Criação científica. Criação artística. Criação de ideias e programas sociais. Criação que é inovação. Colocar o problema do ponto de vista da criação é abrir as universidades a dimensões que nem sempre têm estado presentes na sua vida.

$\mathrm{O}$ segundo diz respeito à reforma dos estudos e à necessidade de colocar $\mathrm{o}$ estudo no centro da actividade universitária. E isto implica uma concepção diferente da pedagogia universitária, que conduza a formas novas de trabalho: o estudo, o estudo acompanhado, a tutoria, a iniciação científica, as novas tecnologias, as redes de aprendizagem, entre outras. É uma mudança decisiva, apenas esboçada nas nossas universidades, que a reitora da Universidade de Harvard sintetizou num discurso intitulado: "We are all teachers and we are all learners". Eis o que nos permite superar dicotomias entre ensino e investigação, mas também entre ensino e aprendizagem, que têm empobrecido a nossa maneira de pensar o trabalho universitário.

Por último, é importante combater o fosso entre a ciência e a universidade, eliminando a divisão entre "ciências" e "humanidades" ou entre investigação fundamental e aplicada. A partir de uma outra perspectiva, é o que nos tem ensinado George Steiner, em particular quando denuncia o buraco negro que se está a criar no centro da estrutura académica europeia. A ciência sem as artes, sem as humanidades, não é nada. É cega. É inútil. Transforma as sociedades do conhecimento em sociedades da ignorância. A universidade só existe se for capaz de acolher e de cultivar estas diferentes lógicas. É o que fazem as grandes universidades do mundo, que não se vergam aos discursos da moda, ao economicismo dominante, à confusão entre universidades e empresas.

P: Qual o papel social e político da Universidade de Lisboa, considerando o fato de, nesses seus 100 anos de existência, ela ter enfrentado por um longo período um regime ditatorial?

AN: Sou a favor de uma maior abertura das universidades à sociedade. Tenho falado muitas vezes da univercidade, isto é, de uma universidade ligada à cidade, à coisa pública. Não basta formar pessoas, é preciso integrá-las na sociedade. Não basta produzir conhecimento, é preciso valorizá-lo do ponto de vista social. Não basta fazer investigação, é preciso transformar o saber em invenção e em inovação.

Em relação ao papel político, dou apenas dois exemplos, entre tantos outros: a Revolução de $\mathrm{Abril}^{3}$ e o processo de integração europeia. ${ }^{4}$ A crise académica de $1962,{ }^{5}$ talvez o acontecimento mais marcante da história da Universidade de Lisboa no século XX, e os movimentos estudantis do final dos anos de 1960 foram decisivos para que Abril se tornasse inevitável e, com ele, o fim da guerra e a liberdade. Por outro lado, a acção realizada na cultura universitária, pelo menos a partir daqueles anos, virou Portugal para a Europa. 
Considero também importante compreender o que se passou, o que é condição para que a infâmia não se repita. Foi o reconhecimento da importância da memória que me levou, no discurso de abertura das Comemorações, no dia 11 de outubro de 2010, a chamar três vezes pela liberdade: liberdade universitária, liberdade das pessoas, liberdade do futuro. E a dedicar o Centenário da Universidade de Lisboa aos professores e estudantes que foram expulsos ou prejudicados nos seus percursos académicos por se terem batido pela liberdade.

P: No cargo de reitor, sei que enfrenta muitos problemas, agendas superabarrotadas, pressões de diversas ordens, reuniões infindáveis, muitas viagens e muitos discursos a serem elaborados, enfim, sei que é uma atividade de muita responsabilidade, de muito trabalho e, muitas vezes, de pouco reconhecimento. Em meio a tudo isso, o senhor sente alguma satisfação por exercer esta função?

AN: Este cargo permitiu-me, dentro dos meus limites, dar ao país um pouco do que ele me deu na minha formação académica, na possibilidade de frequentar universidades estrangeiras, no modo como me abriu as portas de um percurso universitário.

Estou eternamente grato à Universidade de Lisboa por ter confiado em mim, por me ter permitido viver o que de outro modo não teria vivido. Sinto que a minha história se alargou, se enriqueceu, com tudo o que foi possível fazer, mas também com a experiência de muitas incapacidades e insucessos. Percebi bem que a vida se contrai ou se expande proporcionalmente à nossa coragem. Conseguimos, muitas vezes, fazer bons diagnósticos e definir boas soluções. Mas falta-nos, frequentemente, uma ética da decisão, a coragem de fazer aquilo que dizemos que é preciso fazer.

Tenho hoje novos olhares sobre a universidade e sobre a sociedade. E esta é, como diz Proust, a verdadeira viagem da descoberta, que não consiste em encontrar novas paisagens, mas em adquirir novas maneiras de ver e de pensar. Sinto que, quanto mais alto vamos subindo, mais terra vamos avistando, desenhando-se a geografia de tudo o que nos falta ainda percorrer. Só vale a pena assumir responsabilidades de governo de uma universidade se estivermos preparados para enfrentar este dilema e para tentarmos dar resposta às novas exigências e aspirações que surgem, justamente, do nosso próprio progresso.

P: Cada vez mais se ampliam e multiplicam-se os eventos científicos que congregam acadêmicos de Portugal e do Brasil, os chamados colóquios ou congressos luso-brasileiros. Ao lado disso, multiplicam-se os convênios entre universidades, faculdades e departamentos dos dois países, com um elevado número de estudantes e professores brasileiros cruzando o Atlântico para fazerem um curso, um estágio em universidades portuguesas. Como o senhor conhece bem o Brasil e todo este movimento, gostaria que respondesse a duas questões. Primeiramente, gostaria que nos falasse sobre os reais ganhos para o Brasil a partir deste intercâmbio. Em segundo 
lugar, gostaria que desse sua opinião sobre algum aspecto importante a ser levado em conta para a melhoria do ensino superior no Brasil.

AN: As universidades vivem hoje num espaço internacional, que é a sua referência natural. Mas esta internacionalização não pode ser apenas retórica e deve traduzir-se numa colaboração efectiva e concreta. Há duas vantagens que me parecem evidentes. A primeira prende-se com a mobilidade dos estudantes e a possibilidade de incorporar, na sua formação, vivências e experiências absolutamente essenciais para os dias de hoje. A segunda diz respeito aos grandes temas da ciência, e dos cruzamentos interdisciplinares, que hoje exigem uma abordagem interdisciplinar e uma visão que vai muito para além das fronteiras de cada país: o ambiente, a energia, o mar, a demografia etc.

Num outro plano, é útil não esquecer que o mundo se rege por grandes regiões marcadas por línguas e culturas próprias. A afirmação de um espaço lusófono do conhecimento e da cultura, fruto de uma cooperação mais intensa entre universidades brasileiras e portuguesas (e de outros países), é um ganho importante para que a internacionalização não se faça apenas a partir do centro hegemónico do inglês.

\section{P: Para finalizar, com sua experiência no campo da Educação e com seu conhecimento} sobre o Brasil, que conselhos ou sugestões ou pontos para reflexão poderia dar aos dirigentes das universidades públicas brasileiras, considerando tanto as semelhanças como as diferenças entre nosso país e Portugal?

AN: É preciso ser capaz de manter uma tensão inovadora entre a democratização do ensino superior (ao nível da graduação) e programas de formação avançada e de pesquisa audaciosos (ao nível da pós-graduação). Nem sempre é fácil, mas é decisivo.

Por outro lado, é preciso afirmar a autonomia das instituições e combater diariamente todas as formas de ingerência, de burocratização, de asfixia das instituições. A liberdade académica custou muito a conquistar, levou muitos séculos, e é uma invenção, melhor dizendo, uma construção fundamental da ideia de universidade. E, depois, olhar sempre para fora, para o país, para o mundo. Consolidar as nossas forças, a cultura, a ciência, o conhecimento, na perspectiva de uma intervenção social mais crítica e mais esclarecida. Numa universidade, o mais importante é a herança que recebemos e o modo como a legamos às novas gerações. Somos uma instituição que transforma o passado em futuro.

\section{Notas}

1. Tratam-se das seguintes obras: Os professores e sua formação, livro publicado pela editora Dom Quixote, em 1992; O método (auto)biográfico e a formação foi publicado inicialmente pelo Ministério da Saúde de Portugal, em 1988 e, atualmente, é publicado pela editora Paulus, de São Paulo; Profissão 
professor foi publicado pela primeira vez pela Porto Editora, em 1992; Vidas de professores foi também publicado pela Porto Editora em 1992 e As organizações escolares em análise foi publicado pela editora Dom Quixote, também em 1992. Todas estas obras tiveram grande repercussão no Brasil, a partir dos anos de 1990, quando cresce a produção brasileira nesta área.

2. ECTS é uma sigla para European Credit Transfer System (Sistema Europeu de Transferência de Créditos), isto é, um sistema de harmonização da descrição dos planos de estudo e de comparação entre números de horas de ensino e de estudo necessários para obter aprovação numa disciplina.

3. O entrevistado se refere à Revolução de Abril de 1974, que pôs fim ao regime ditatorial vigente no país desde 1933.

4. Portugal entrou para a Comunidade Econômica Europeia (CEE) em 1986.

5. É chamada de "crise acadêmica de 1962" uma série de conflitos ocorridos naquele ano entre os estudantes universitários portugueses e o regime do Estado Novo. 